\title{
Stability behavior and Thermodynamic States of Iron and Manganese in Sandy Soil Aquifer, Manukan Island, Malaysia.
}

\begin{abstract}
A total of 20 soil samples were collected from 10 boreholes constructed in the low lying area, which included ancillary samples taken from the high elevation area. Redox processes were investigated in the soil as well as groundwater in the shallow groundwater aquifer of Manukan Island, Sabah, Malaysia. Groundwater samples $(n=10)$ from each boreholes were also collected in the low lying area to understand the concentrations and behaviors of Fe and $\mathrm{Mn}$ in the dissolved state. This study strives to obtain a general understanding of the stability behaviors on $\mathrm{Fe}$ and $\mathrm{Mn}$ at the upper unsaturated and the lower-saturated soil horizons in the low lying area of Manukan Island as these elements usually play a major role in the redox chemistry of the shallow groundwater. Thermodynamic calculations using PHREEQC showed that the groundwater samples in the study area are oversaturated with respect to goethite, hematite, $\mathrm{Fe}(\mathrm{OH}) 3$ and undersaturated with respect to manganite and pyrochroite. Low concentrations of $\mathrm{Fe}$ and $\mathrm{Mn}$ in the groundwater might be probably due to the lack of minerals of iron and manganese oxides, which exist in the sandy aquifer. In fact, high organic matters that present in the unsaturated horizon are believed to be responsible for the high $\mathrm{Mn}$ content in the soil. It was observed that the soil samples collected from high elevation area (BK) comprises considerable amount of $\mathrm{Fe}$ in both unsaturated $(6675.87 \mathrm{mg} / \mathrm{kg})$ and saturated horizons $(31440.49 \mathrm{mg} / \mathrm{kg}$ ) compared to the low Fe content in the low lying area. Based on the stability diagram, the groundwater composition lies within the stability field for $\mathrm{Mn} 2+$ and $\mathrm{Fe} 2+$ under suboxic condition and very close to the $\mathrm{FeS} / \mathrm{Fe} 2+$ stability boundary. This study also shows that both $\mathrm{pH}$ and Eh values comprise a strong negative value thus suggesting that the redox potential is inversely dependent on the changes of $\mathrm{pH}$.
\end{abstract}

Keyword: Stability behaviors; Small island; Groundwater thermodynamic states; Redoxsensitive minerals; Stability diagrams; PHREEQC. 